\title{
Spatiotemporal Modelling of Nitrate and \\ Orthophosphate Concentrations in Aquatic Ecosystems
}

\author{
Jude Eze (Corresponding Author) \\ School of Mathematics and Statistics \\ University of Glasgow, G12 8QW, Scotland
}

Tel: 44-141-330-7563E-mail: jude.eze@glasgow.ac.uk

Marian Scott

School of Mathematics and Statistics

University of Glasgow, G12 8QW, Scotland

Tel: 44-141-330-5125Ｅ-mail: Marian.Scott@glasgow.ac.uk

Adrian Bowman
School of Mathematics and Statistics
University of Glasgow, G12 8QW, Scotland
41-330-4046 E-mail: Adrian.Bowman@glasgow.ac.uk

Mark Hallard

Scottish Environment Protection Agency

Bremner House, Castle Business Park, Stirling FK9 4SW, Scotland

\author{
Claire Miller \\ School of Mathematics and Statistics \\ University of Glasgow, G12 8QW, Scotland
}

Tel: 44-141-330-5023Ｅ-mail: Claire.Miller@glasgow.ac.uk

\author{
Duncan Lee \\ School of Mathematics and Statistics \\ University of Glasgow, G12 8QW, Scotland
}

Tel: 44-141-330-4047Ｅ-mail: Duncan.Lee@glasgow.ac.uk 


\title{
Macrothink
}

Received: March 26, 2012 Accepted: April 30, 2012 Published: December 1, 2012

doi:10.5296/jee.v3i1.1555

URL: http://dx.doi.org/10.5296/jee.v3i1.1555

\begin{abstract}
A study of the temporal and spatial variations of Total Oxidized Nitrogen (TON) and orthophosphate in freshwater bodies within the boundaries of the Loch Lomond and Trossachs National Park (LLTNP) is described. A hierarchy of temporal and spatiotemporal additive models (AM) and additive mixed models (AMM), using spline smoothing, were fitted to the data to explore trends, seasonality and variation. Individual site analyses of both determinands show different temporal behaviour across sites. Temporal and seasonal patterns also differ by site group - rivers, lochs and sewage treatment works (STW). Overall, TON concentrations in the rivers and lochs are declining but increasing at the STW sites. Orthophosphate time trends are similar in the three groups except that concentrations in rivers and lochs show signs of an increase from 2006. Seasonal patterns are apparent, with the concentration of orthophosphate at a maximum in summer and lowest in winter in rivers and STW sites. In contrast, the seasonal peak in the lochs is in late winter/spring. TON is higher in winter with lowest levels in the late summer/autumn in the rivers and lochs. At the STW sites, the highest levels were found in the summer and the lowest levels in the winter. The effects of nitrogen deposition and total weekly rainfall on TON depend on their interactions with different categories of land cover. This study is part of an assessment of the effects of regulatory efforts of Environmental Agencies to improve water quality in the region.
\end{abstract}

Keywords: Additive mixed effect models, Penalized regression splines, Water quality, Total Oxidized Nitrogen 


\section{Introduction}

Water quality is an important environmental variable which may be adversely affected by nutrients such as nitrate and phosphate entering water bodies as both diffuse and point sources of pollution, potentially leading to eutrophication. European legislation (Water Framework Directive, 2000) requires that all shallow water bodies achieve good ecological status by 2015. Also, the urban waste water treatment directive (1991), requires that the environment be protected against the adverse effects of waste water discharges by collecting and appropriately treating waste water in order to reduce nitrate and phosphorus concentrations before it is discharged into the environment, unless there is proof that it will have no effect on eutrophication. The implementation of these directives requires, in part, the monitoring of some determinands of nutrient enrichment. Information gathered from monitoring these determinands forms the basis of classification of the water bodies (Water Framework Directive (WFS)).

Different levels of nutrient enrichment of freshwater bodies may give rise to different biological changes in the water body. For instance, well-oxygenated fresh waters are known to be associated with low levels of phosphorus and nitrogen and these low levels can also limit production in freshwater ecosystems. On the other hand, excessive nutrient loading leads to rapid increases in water plants, algae and a deterioration of oxygen which in turn leads to biodiversity loss and poor water quality, resulting from toxic algal and cyanobacterial blooms (Ricklefs 1993).

Several studies (Clark et al. 2004; Paiseley et al. 2003; Johnes and Butterfield 2002; Fisher and Oppenheimer 1991) examined the sources of stream nitrates and their association with some catchment characteristics, and found that aquatic nitrogen loading could be influenced by anthropogenic sources, dry nitrogen deposition, air temperature, soil type and land use. Studies have also investigated spatial patterns of nitrate across catchments (King et al 2005), while other studies were concerned with temporal variations in concentrations (Howden and Burt 2009; Weyhenmeyer et al, 2007), including incorporation of river flow.

Utilization of phosphorus by biotic components has been studied (Chakrabarty 2006), and attempts have been made to predict phosphorus loading through diffuse and point sources from agricultural areas and sewage treatment works (Heathwaite et al 2005; Kinniburgh et al 1997). Ferrier et al (2001) studied the spatial and temporal trends of water quality of Scottish rivers using data from the Harmonised Monitoring Scheme (HMS) between 1974 and 1995 in 56 rivers. They used principal component and correlation analysis to identify relationships between different catchments and water quality determinands and concluded that different types of catchment systems can be identified by land cover characteristics and that this reflected in the water quality determinand concentration signals. Specifically, they found that nitrate concentrations were highly correlated with the amount of arable land and that relationships exist between grassland cover, orthophosphate and suspended solid concentrations. Urban catchments were associated with ammonium-N, orthophosphate and suspended solids. Studies have shown that retention capacity of deposited nitrogen may vary 
by vegetation type (Curtis et al 2005) and also by plantation age (Emmett et al 1993). Therefore, the run-off effect of rainfall may depend also on the vegetation type.

A study of the spatiotemporal variations of Total Oxidized Nitrogen (TON) and orthophosphate within the boundaries of the Loch Lomond and the Trossachs National Park (LLTNP), in the west of Scotland is described. Models are developed to describe trends and seasonality of each determinand. The extent to which concentration levels are driven by catchment and climatic covariates is examined in order to highlight the association between trends in water quality and the environment. Therefore, the motivation of this paper is to: a) demonstrate how data from different sources and with different (spatial and temporal) dimensions could be integrated in a statistical analysis, b) describe trends and seasonality of nutrients and c) identify the influence of covariates on patterns of nutrient concentrations.

We postulate that nutrient levels in these surface waters may differ between sites and that levels may depend on the dominant land cover type, the interactions between nitrogen deposition with land cover and rainfall.

\section{Background}

The region of interest for this study is located in the west of Scotland, and covers an area of about $720 \mathrm{sq}$ miles $(1,865 \mathrm{sq} \mathrm{km})$ with a boundary that extends to 220 miles $(350 \mathrm{~km})$. It was designated in July 2002 as a National Park - the first in Scotland. The boundary map of the park is shown in Figure 1. There are about 22 large lochs including Loch Lomond which has the largest expanse of freshwater in the UK and 50 rivers (State of Park report, 2005). The park attracts more than two million visitors every year. There are 61 Sites of Special Scientific Interest (SSSI), 8 Special Areas for Conservation (SAC) for endangered and vulnerable natural habitats and 1 Special Protected Area (SPA) for wild birds within the park. The park supplies about 593 megalitres of water to more than one million people and the hydro-electric power station at Loch Sloy generates about 152.5 MW of electricity (Bell, 2006). Therefore, given the strategic importance of the region, it is expedient to consider carrying out a holistic assessment of the park's environment using routinely available data. In this study we focus on water quality which can serve to some extent, as a proxy indicator of environmental quality of the region.

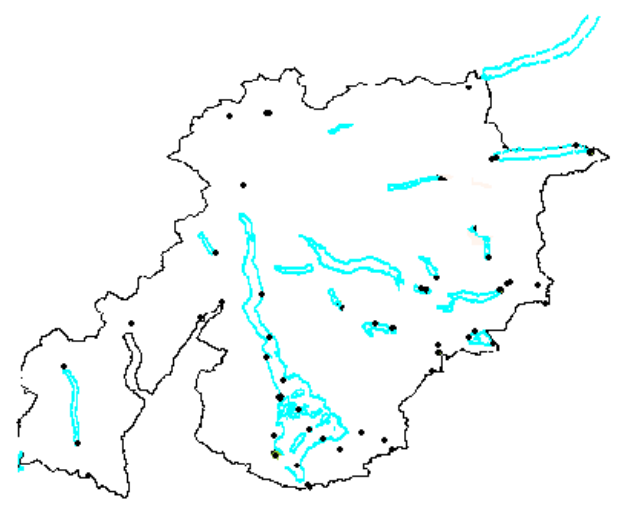

Figure 1. Map of the National Park showing some of the lochs. River networks are not shown.

The dots are the positions of river, STW and loch sites covered in this investigation. 


\section{Materials and Methods}

The data used for this study were supplied by the Scottish Environment Protection Agency (SEPA), from their routine monitoring programme, and comprise 56 sites (20 lakes, 25 rivers and 11 sewage treatment discharge sites) at which nitrates and phosphates are measured. Most of the sites have data collected approximately monthly from 1998 to 2009. These sites are a subset of about 289 sites within the region. Only sites with at least 40 observations between 1998 and 2009 were included in the study. Imputation of measurements recorded as censored below some detection limits was conducted using the Regression on Order Statistics (ROS) method (Lee and Helsel 2005).

A review of the relevant literature reveals that major sources of nitrate and orthophosphate in freshwaters include sewage treatment effluent discharges, runoff from agricultural sites, lawn fertilizer application, decaying plant and animal remains/droppings and phosphate rocks. Consequently, data on total weekly rainfall, nitrogen deposition and land cover were also collected. Rainfall data were obtained from the Met Office for five stations within the park. Weekly total rainfall at these five Met stations was taken as a surrogate measure of weekly rainfall for the water monitoring sites closest to them. Nitrogen deposition was downloaded from the Air Pollution Information System (APIS) website, maintained by the Centre for Ecology and Hydrology (CEH). Flow information was available for only four river sites. Information on land cover, based on UK broad habitat classifications was obtained from the land cover map 2000 (CEH 2000). For this region, eight major land cover classes were identified, and these include broad leaf woodland, coniferous woodland, improved grass, neutral grass, calcareous grass, acid grass, montane habitat and shrub. Data on land use were not available. The choice of these catchment and climate covariates was informed by the need to understand their respective contribution to variations in Total Oxidized Nitrogen (TON) and orthophosphate in the region and also recognising the importance of integrating land and water management.

The chemical determinands and rainfall are measured over time and space while nitrogen deposition and land cover have no temporal component. Nitrogen deposition was reported in $\mathrm{kg} \mathrm{N} / \mathrm{ha} /$ year while land cover is based on the UK broad habitat classification of 2000 . The integration of these data in the same statistical model was based on the assumption that land cover and nitrogen deposition level at each site remains unchanged over the years. This is informed by the fact that no major physical developments that would alter the land cover and deposition levels are known to have taken place within the vicinity of the park in the time period covered by our investigation.

A hierarchy of temporal and spatiotemporal additive and additive mixed models using smooth spline basis functions were fitted to the data to explore trends and variation (Models 1 through 3). Circular smoothers were used for seasonal terms (day of the year). A simple temporal trend model (1) formed the basis of the hierarchy of models. For sites where data on mean daily flow were available, model (1) was extended to incorporate a smooth function of $\log$ mean flow. Thus, our site-specific model is similar to that of Howden and Burt (2009). The difference between the two modelling approaches however, is that for all models, we 
adopted a flexible nonparametric penalized regression spline approach which does not constrain the relationships between the determinands and the explanatory variables to be linear; each covariate is represented as a smooth term. Model parameters were estimated by penalized likelihood; for further information, see Wood (2006). The site specific model is

$\log \left(y_{i}\right)=\mu+s\left(\right.$ doy $\left._{i}\right)+s\left(\right.$ year $\left._{i}\right)+\varepsilon_{i}$

$i=1,2,3, \ldots \ldots . ., n$, where $n$ is the number of observations at the site, $y_{i}$ is the observed value of the determinand at time $i, \mu$ is the overall mean of the determinand over the sampled period in each site, year $=$ year + doy/365, doy $=$ day of year, $s$ denotes smooth terms and $\varepsilon_{i} \sim N\left(0, \sigma_{w}^{2}\right)$ are random errors assumed to be independent. Year represents the effect of time trend and doy accounts for the seasonal effect on the response variable $y$. Natural log transforms of TON and orthophosphate were applied to reduce skewness and stabilize the variance over time.

A spatiotemporal additive mixed effect model was fitted to the different classifications of the monitoring sites (lochs, rivers and STW), which included a random site effect, site, as shown in model (2). Interest here is in variability across sites and this is accounted for by the site specific random effect term in the model. The three nonparametric smooth terms in the model are fixed effects. The spatial smooth term is a fixed term that estimates the average spatial effect of the sites included in the analysis while site is the random effect associated with a particular monitoring station, beyond the pattern explained by the smooth spatial terms.

$$
\log \left(y_{i j}\right)=\mu+s\left(\text { doy }_{i j}\right)+s\left(\text { year }_{i j}\right)+s\left(\text { Easting }_{j}, \text { Northing }_{j}\right)+\text { site }_{j}+\varepsilon_{i j}
$$

$i=1,2,3, \ldots ., n, j=1,2,3, \ldots \ldots ., J$, where $n$ is number of observations in the group of interest, $J$ is the number of sites in the group, $y_{i j}$ is the determinand at time $i$ in site $j$. The site term is a random effect with a $N\left(0, \sigma_{\mathrm{b}}^{2}\right)$. The within-group variation is described as $\varepsilon_{i j} \sim N\left(0, \sigma_{w}^{2}\right)$.

The Easting and Northing are spatial coordinates representing the location of the sites in geographical space.

Finally, covariate effects of nitrogen deposition, rainfall and land cover were examined by extending model (2) to model (3), which was also fitted to each of the three groups. For brevity, we have written subsequent equations without subscripts.

$$
\begin{aligned}
\log (y)= & \mu+s(\text { doy })+s(\text { year })+s(\text { rainfall })+s(\text { Ndeposition })+s(\text { Ndeposition }): \text { land cov er } \\
& +s(\text { rainfall }): \text { land cov } e r+s(\text { rainfall, Ndeposition })+\text { land cover } \\
& +s(\text { Easting }, \text { Northing })+\text { site }+\varepsilon
\end{aligned}
$$

Land cover was fitted as a factor with eight levels. Hence, model (3) fits smooth-factor interactions and obtains a separate centred smooth for each category of land cover. The 
rainfall-nitrogen deposition interaction is intended to reflect the changes in the effect of nitrogen deposition on TON due to varying quantities of rainfall. The land cover interaction with nitrogen deposition accounts for possible up-take of deposited nitrogen by catchment vegetation which is expected to differ depending on vegetation type. Also, the run-off effect of rainfall may depend on the type of land cover prevalent in the catchment. Model (3) was specifically fitted to TON. A modified version, without $\mathrm{N}$ deposition, was fitted to orthophosphate.

Analysis of the three models was conducted using the mgcv package for $R$ (Wood, 2006). Generalized Cross Validation (GCV) was used to select the smoothing parameters. A grid search using the prediction error criteria is performed in order to find the model that minimizes the GCV score. Model degrees of freedom are affected by penalisation during fitting and different penalties yield different smoothing parameters. Consequently, mgcv reports the effective (estimated) degrees of freedom (edf) for each smooth term and each model coefficient. Model smoothness is controlled by fixing the basis dimension at a size slightly larger than is considered necessary and adding a penalty to the least squares fitting criterion to penalize the model for wiggliness.

Minimization of the GCV score could be achieved using performance iteration as suggested by $\mathrm{Gu}$ (1992) where the smoothing parameters are estimated at each iteration as part of penalized iteratively reweighted least squares (PIRLS) minimization based on Newton's methods or outer iteration (O'Sullivan et al. 1986) which uses finite-difference based gradients. Wood $(2004,2008)$ gave a more stable and fast smoothness selection approach which avoids the updating of the smoothing parameter values, recalculation of parameter values and the accumulation of various derivatives in the PIRLS iteration process as obtained in the performance and outer iteration procedures. The new method, which is available in the mgcv package, runs the PIRLS with fixed smoothing parameters until convergence. Readers interested in the detailed description of the smooth parameter selection algorithm should see Wood (2008, 2006, 2004, 2002 and 2000).

Models were compared using GCV score, Akaike Information Criteria (AIC) and generalized likelihood ratio tests (GLRT). The model with the lowest GCV score and AIC was chosen as the better model. In some cases, the generalized likelihood ratio test was used for selecting the best model or assessing the significance of a covariate introduced into the model.

\section{Results}

\subsection{Site Specific Analysis}

Preliminary analysis indicates that the highest concentrations of TON and orthophosphate were found among the sewage treatment work sites. Results obtained by fitting the site specific model (1) show different temporal and seasonal behaviour across sites for the two determinands. We have chosen at least one site from each group of sites to depict the difference in behavioural patterns across groups. Figures 2 and 3 represent the different seasonal and temporal patterns of TON and orthophosphate at four sites respectively. The solid lines in the plots are the seasonal or time trend effects respectively. The dashed lines 
indicate two standard errors from the estimates and the points are model partial residuals. A close investigation indicates that the seasonal patterns differ depending on whether the site is a river, loch or STW site.

For TON, peak concentrations at the STW sites (where a seasonal pattern exists) are in the summer. This is the opposite of the patterns observed in the rivers and lochs where lowest levels were observed in the summer/autumn. Orthophosphate seasonal patterns are fairly similar across sites where they exist, peaks are in summer. Except for a few sites, the two determinands showed decreasing trends over the years.

Table 1. P-values and adjusted $R$-squared from model (1) for some sites

\begin{tabular}{|l|l|l|l|l|l|l|l|l|}
\hline \multicolumn{2}{|l|}{ TON } \\
\hline Site & $\begin{array}{l}\text { Loch } \\
\text { Ard }\end{array}$ & $\begin{array}{l}\text { Luss } \\
\text { STW }\end{array}$ & $\begin{array}{l}\text { Endrick } \\
\text { Drymen }\end{array}$ & $\begin{array}{l}\text { Catter } \\
\text { Burn }\end{array}$ & $\begin{array}{l}\text { Loch } \\
\text { Chon }\end{array}$ & $\begin{array}{l}\text { Kinlochard } \\
\text { STW }\end{array}$ & $\begin{array}{l}\text { Endrick } \\
\text { Drymen }\end{array}$ & Fillan \\
\hline $\begin{array}{l}\text { Season } \\
\text { Trend } \\
\mathrm{R}_{\text {adj }}^{2}\end{array}$ & 46.001 & 0.0002 & 0.0196 & 0.008 & 0.0068 & 0.0162 & 0.3695 & 0.0197 \\
\hline & 46.001 & 0.1500 & 0.1141 & 0.003 & 0.0225 & $<0.001$ & 0.0276 & 0.0076 \\
47.5 & 31.8 & 41.4 & 26.4 & 45.6 & 16.5 & 49.7 \\
\hline
\end{tabular}

Table 1 shows the $p$-values for the trend and seasonal effects and adjusted R-squared from fitting model (1) to the two determinands for some selected sites. Trend and/or seasonal effects are statistically significant in $90 \%$ and $83 \%$ of the TON and orthophosphate sites respectively.

The variation in the determinands explained by the additive effects of trend and season is not particularly high at some sites. For TON, the explained variability is at least $40 \%$ in about half (49 percent) of the sites, ranging from $5 \%$ to $64 \%$. The $R$-squared adjusted values range from $8 \%$ to $81 \%$ for orthophosphate sites with about 40 percent of the sites having values above $40 \%$. This tends to suggest the need to search for other factors that may contribute to the variability in addition to season and trend. 

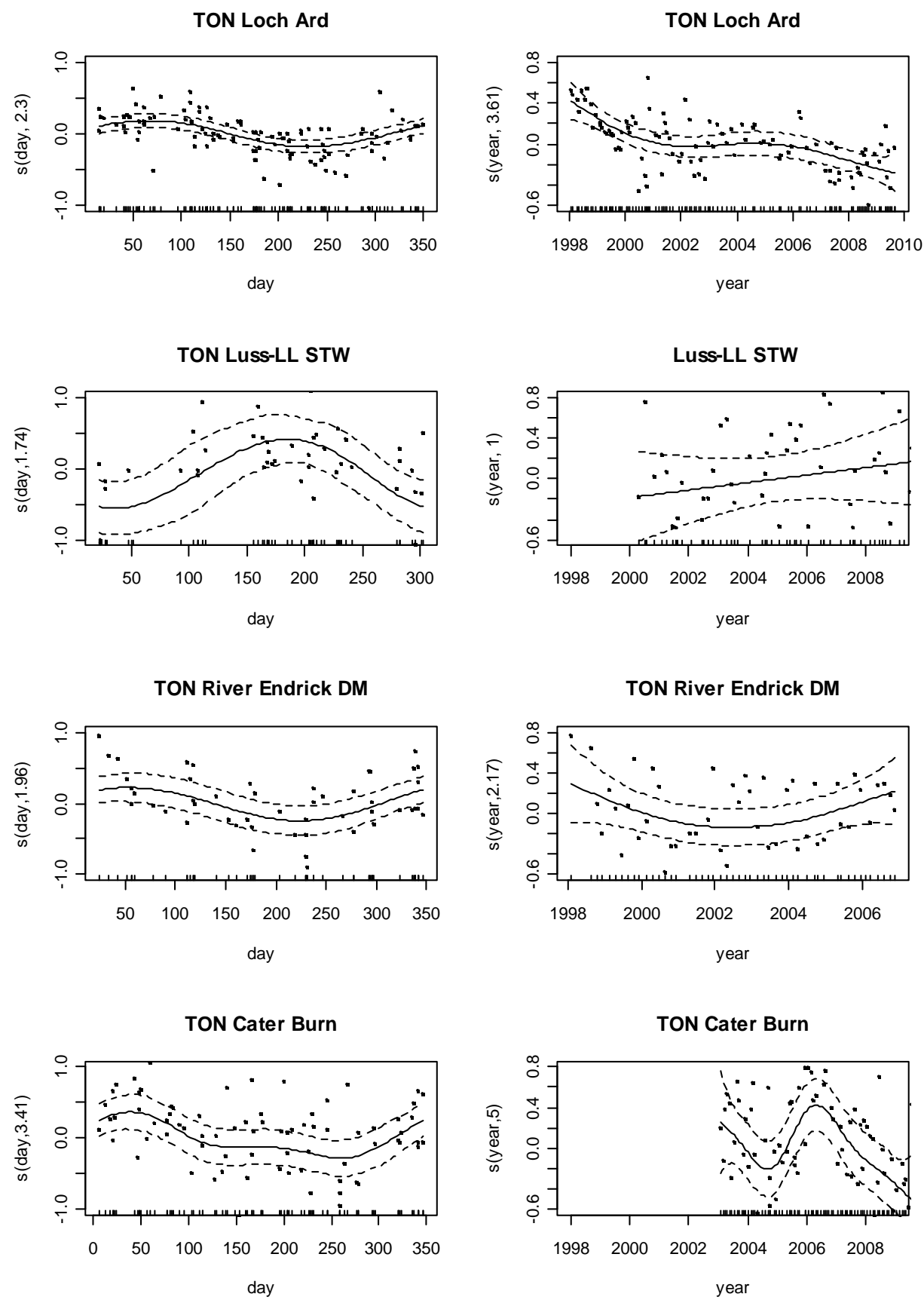

Figure 2. Seasonal (first column) and trend (second column) effects obtained from model (1) fitted to TON for the sites. Dashed lines denote two standard errors from the estimate. The points denote model partial residuals. The label on the y-axis refers to the smooth effect of covariates: s(covariate, edf). 

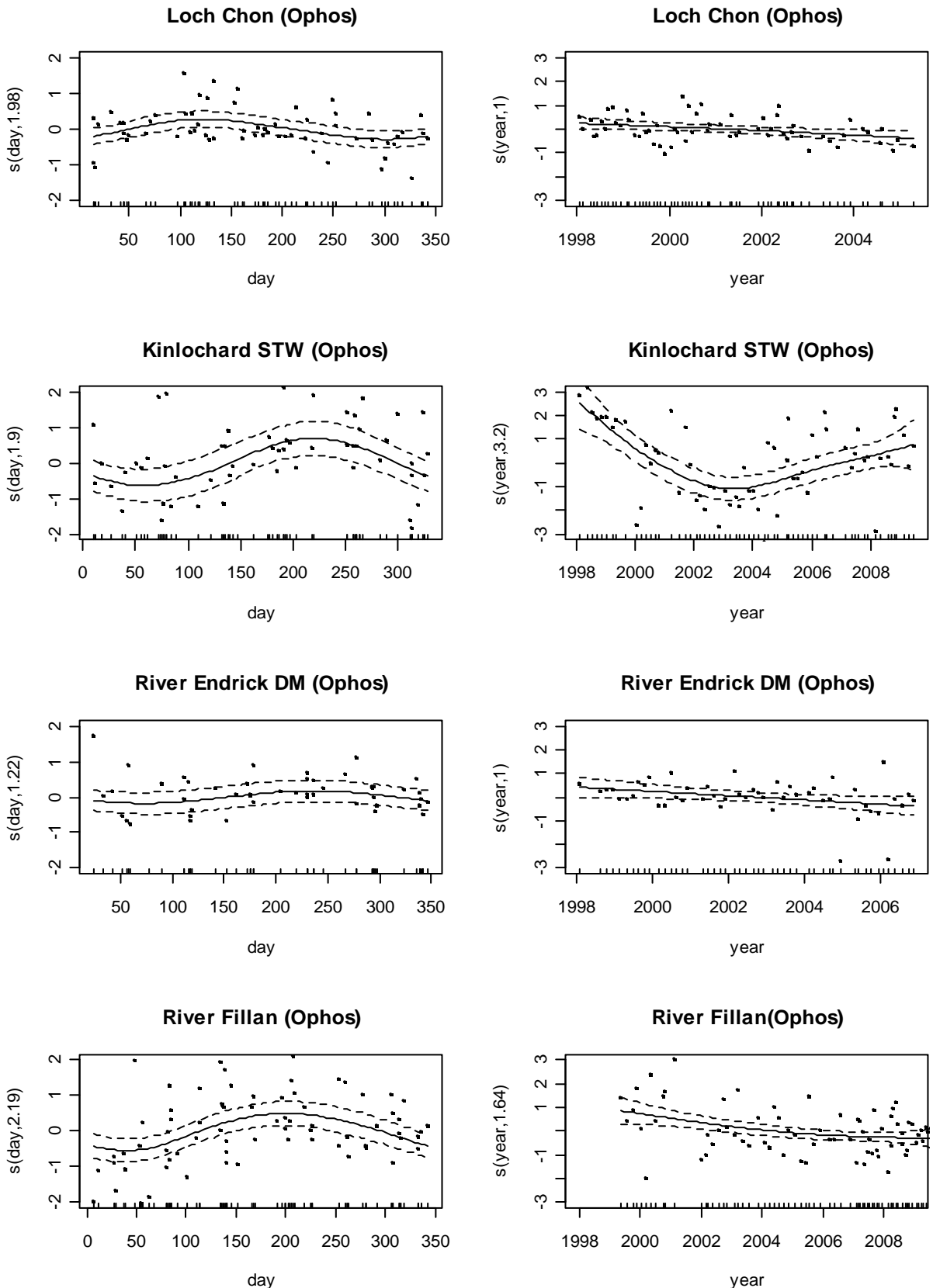

Figure 3. Seasonal (first column) and trend (second column) effects obtained from model (1) fitted to orthophosphate (ophos). Dashed lines are two standard errors from the estimate. The points are model partial residuals. The y-axis shows the smooth effect of the covariates on the response: s(covariate, edf).

\subsection{Spatiotemporal Analysis}

Analyzing the freshwater groups by fitting the spatiotemporal mixed effect model (2) to each group gave the results shown in Figures 4 and 5 and Table 2. 

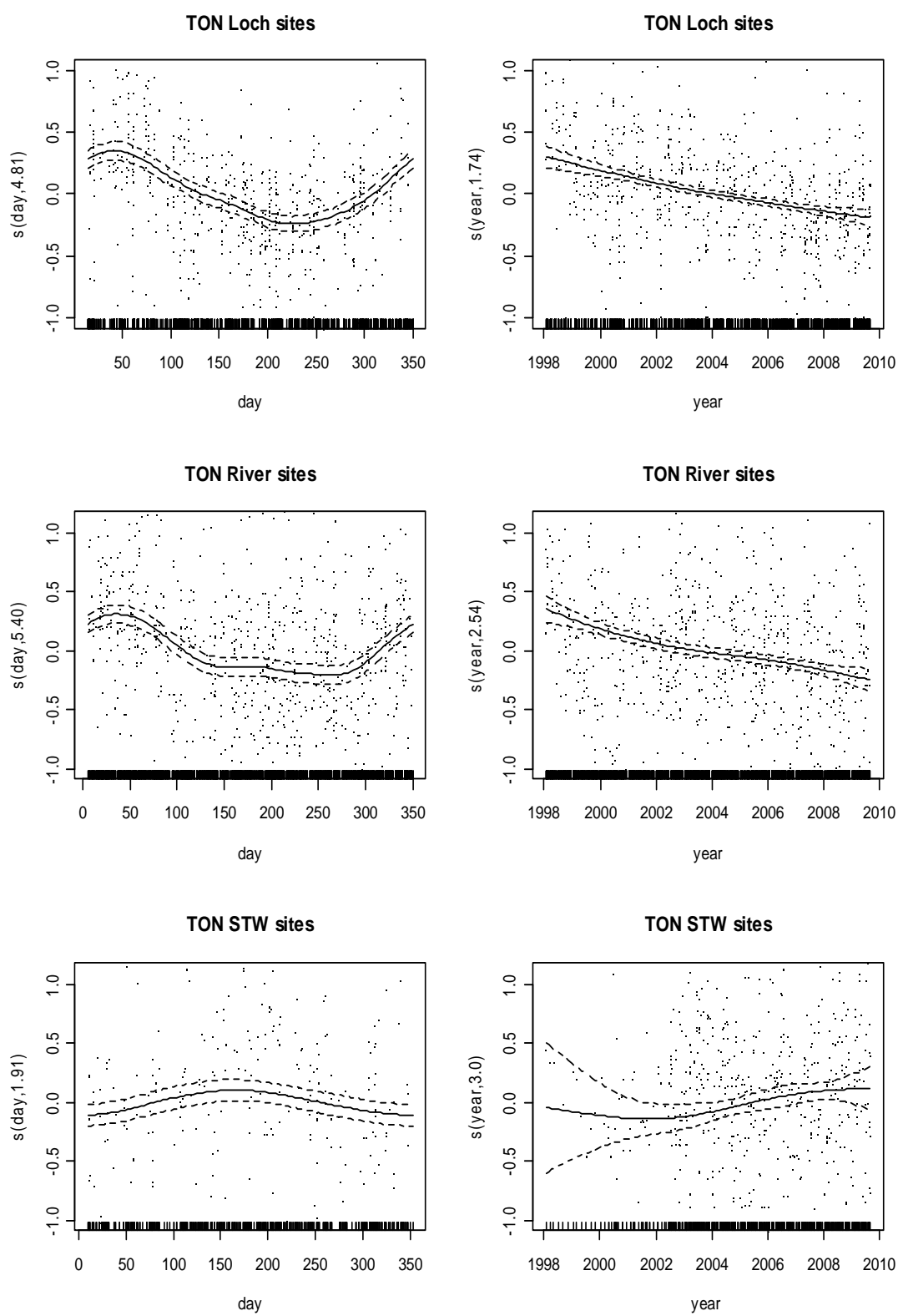

Figure 4. Seasonal (left) and trend (right) components obtained from model (2) fitted to TON in the freshwater groups. The dashed lines are two standard errors from the estimates; the points are partial residuals. 


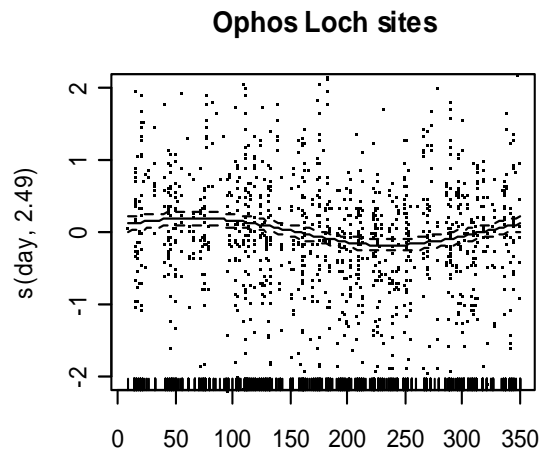

day

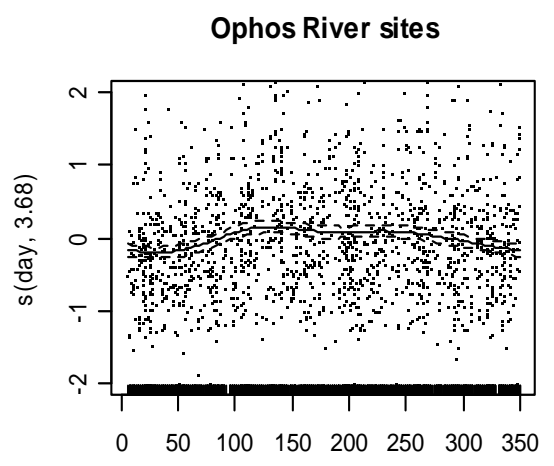

day

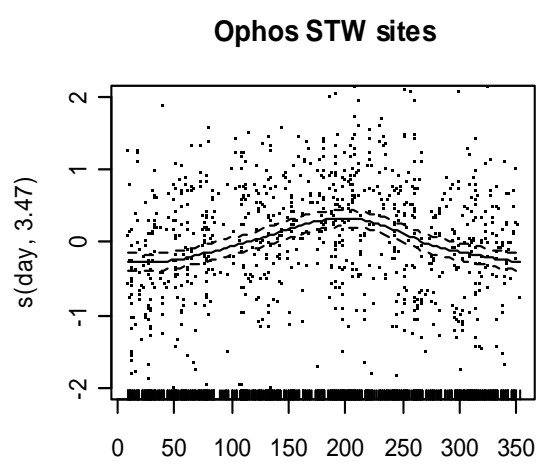

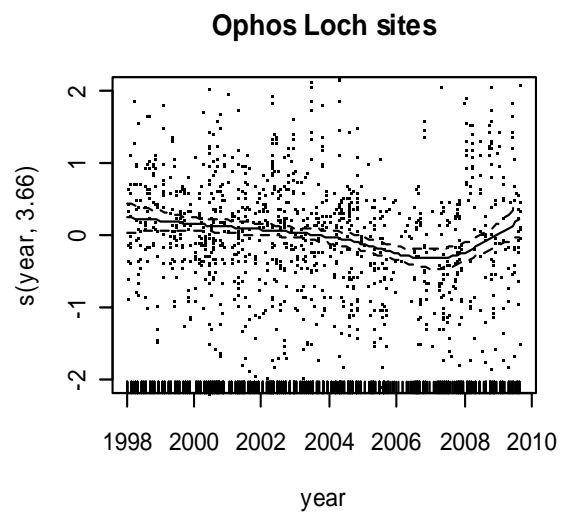

Ophos River sites

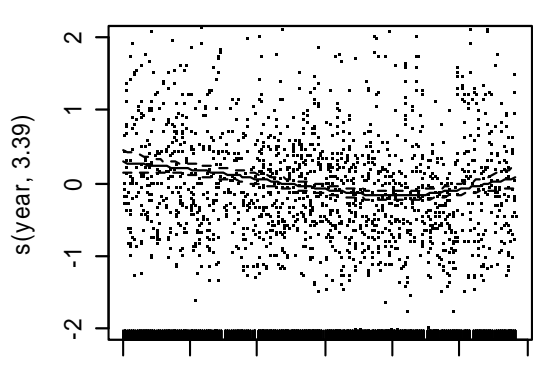

1998200020022004200620082010

year

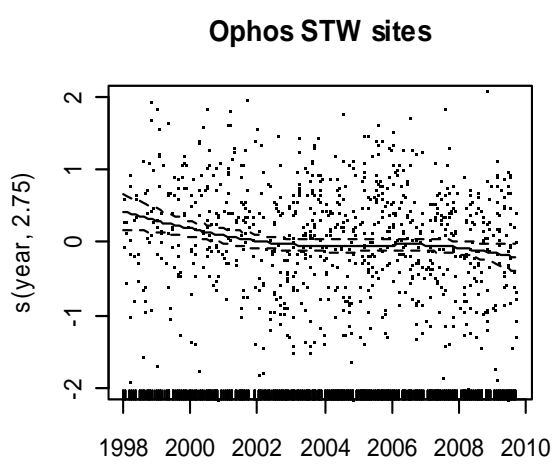

Figure 5. Seasonal (left) and trend (right) effects obtained from model (2) fitted on orthophosphate in the freshwater groups. The points are the partial residuals.

Table 2 shows that the p-values of the smooth terms in the river and loch groups are all significant. The spatial effect is not significant in the STW group. Differences in seasonal and temporal behaviours among the groups are obvious in the graphs. For TON, patterns observed in the sewage treatment works group are different from that of river and loch groups. The average peak concentration of TON in the sewage treatment sites is in the summer while for river and loch groups, the peak concentrations are in the winter. Also, over the years, levels are on the decline in the rivers and lochs while increasing for the STW sites. The large variability in the trend estimates between 1998 and 2002 in the STW sites as shown in Figure 4 is due to fewer observations available for the period. 
Table 2. Smooth term p-values, between $\left({ }^{\sigma_{b}}\right)$ and within-group $\left({ }^{\sigma_{w}}\right)$ standard deviations from model (2). Percentage of variability of the error term due to the random effect is in brackets.

\begin{tabular}{|l|l|l|l|l|l|l|}
\hline \multirow{2}{*}{$\begin{array}{l}\text { Model } \\
\text { term }\end{array}$} & \multicolumn{2}{|l|}{ TON } & \multicolumn{2}{|l|}{ Orthophosphate } \\
\cline { 2 - 7 } & Lochs & Rivers & STW & Lochs & Rivers & STW \\
\hline Season & $<0.001$ & $<0.001$ & 0.0144 & $<0.001$ & 0.0017 & $<0.001$ \\
Trend & $<0.001$ & $<0.001$ & 0.0090 & $<0.001$ & $<0.001$ & 0.004 \\
Space & $<0.001$ & $<0.001$ & 0.7609 & $<0.001$ & $<0.001$ & 0.336 \\
\hline$\sigma_{\mathrm{b}}$ & 0.229 & 0.476 & 1.639 & 0.145 & 0.365 & 1.507 \\
$(12.7)$ & $(28.9)$ & $(81.1)$ & $(2.5)$ & $(15.6)$ & $(72.2)$ \\
\hline$\sigma_{\mathrm{w}}$ & 0.601 & 0.746 & 0.791 & 0.897 & 0.849 & 0.934 \\
& $(87.3)$ & $(71.1)$ & $(18.9)$ & $(97.5)$ & $(84.4)$ & $(27.8)$ \\
\hline
\end{tabular}

Analysis suggests late winter peak concentrations in the seasonal pattern of orthophosphate in the lochs with lowest levels in late summer. However, average levels peak in the summer in both rivers and sewage treatment work sites and are lowest in the winter. Trends are fairly similar in the three groups except that estimates for the river and loch sites appear to suggest that levels have been increasing since 2006. Between-site variation, as shown in the second to last row of Table 2, is largest among the STW sites where it accounted for about 81.1 and 72.2 percent of the random variation in the error term in TON and orthophosphate respectively. Within group variation is higher in the lochs and rivers. Spatial effects are higher among river and loch sites located in the eastern part of the region. This may be partly explained by their proximity to STW sites, most of which are located in the east.

\subsection{Covariate Effects}

It is also of interest to investigate the drivers that may have influenced the observed patterns in TON and orthophosphate. Consequently, we extended model (1) to incorporate a smooth term of $\log$ mean daily flow in the model for the four sites where flow data were available. The effect of mean daily flow was statistically significant in two (Forth and Endrick) of the four sites for both TON and orthophosphate; See Figure 6. We have only shown these two sites where flow is significant for TON. 

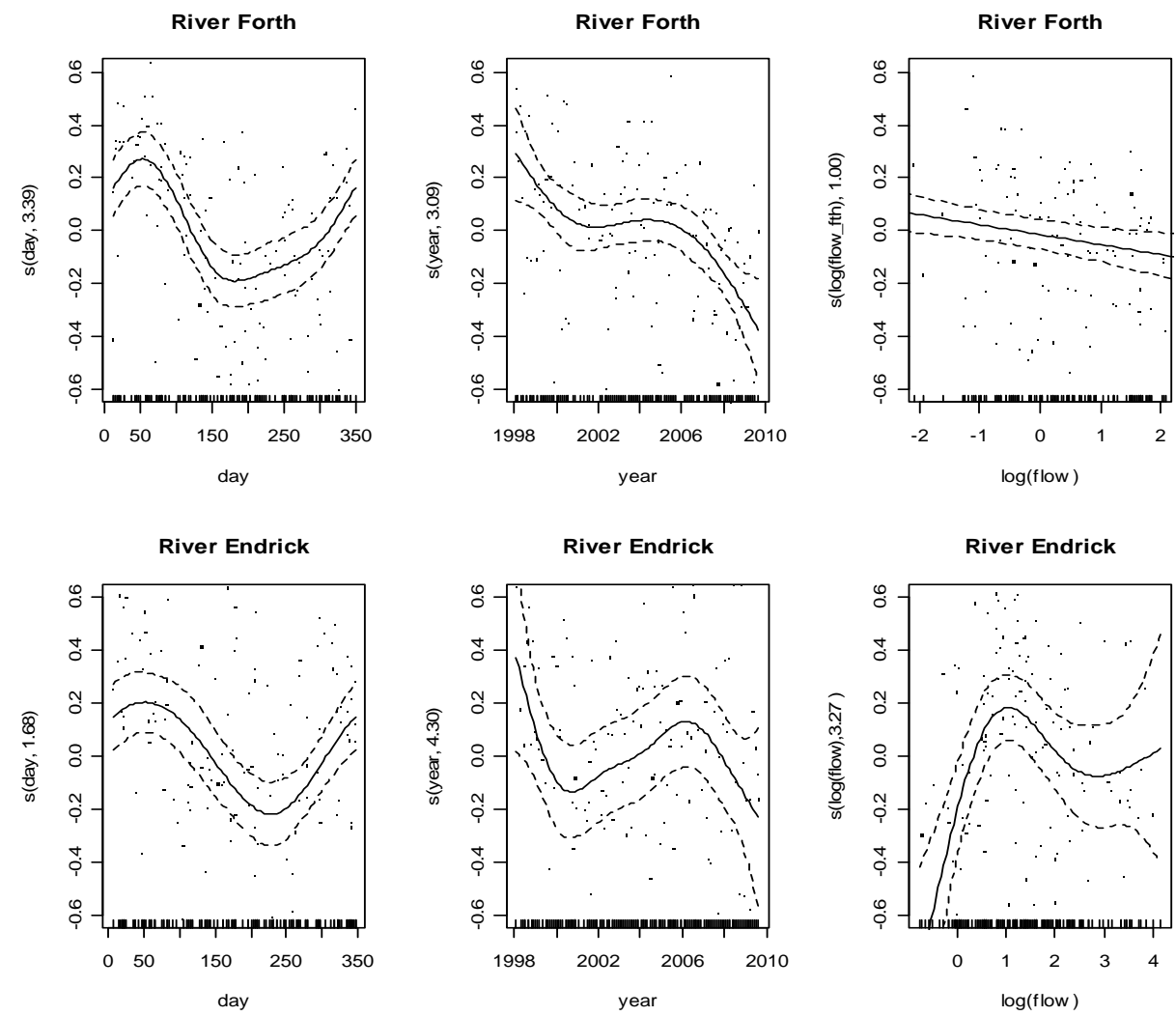

Figure 6. Seasonal (left), trend (middle) and flow (right) effects obtained from model (1) that incorporates $\log$ flow fitted on TON in two sites.

The flow effect at the River Forth shows a negative association between log mean daily flow and concentration levels of TON and orthophosphate while, for River Endrick, the effect was positive for low levels of flow. The third column of Figure 6 highlights the effect of log mean daily flow on TON in the two sites. It is interesting to note that seasonal effects are still significant even after adjusting for the flow effect in each site. Slight improvements were noted in the adjusted R-squared in the sites as a result of incorporating mean daily flow in model (1).

Model (3), which accounts for the effect of rainfall, land cover, nitrogen deposition and interactions, was fitted to the two determinands in the three freshwater groups. Fitting model (3) to both determinands revealed that the spatial coordinates (represented by Easting and Northing) are highly correlated with land cover. Also, the covariate interactions appear to have mopped up any site random effect. Consequently, the spatial smooth term and site random effect were removed from the final model as shown in model (4).

$$
\begin{aligned}
\log (y)= & \mu+s(\text { doy })+s(\text { year })+s(\text { rainfall })+s(\text { Ndeposition })+s(\text { Ndeposition }): \text { landcover } \\
& +s(\text { rainfall }): \text { landcover }+s(\text { rainfall }, \text { Ndeposition })+\text { landcover }+\varepsilon
\end{aligned}
$$

The results from the final model (4) are displayed in Figure 7 and Table 3 for TON only. However, results will be discussed for both determinands. 
The parametric estimates of the seven land cover factor levels shown in the top part of Table 3 were compared to the first level (broad leaf land cover). Hence, relative to broad leaf, conifer, improved grass, calcareous grass, acid grass and montane habitat were associated with TON. The levels of TON in the rivers were significantly associated with nitrogen deposition and the nature of this association is different for different land cover types. This is shown in Table 3 by the interaction terms between land cover and nitrogen deposition and rainfall.

Table 3. Covariate effects from model (4) fitted to TON. The seven land cover categories shown as parametric terms are compared with broad leaf woodland.

\begin{tabular}{|l|c|}
\hline Parametric terms & P-values \\
\hline Coniferous woodland & $<0.001$ \\
Improved grass & $<0.001$ \\
Neutral grass & 0.1417 \\
Calcareous grass & 0.0272 \\
Acid grass & 0.0180 \\
Shrub & 0.1231 \\
Montane habitat & $<0.001$ \\
Smooth terms & $<0.001$ \\
Season & $<0.001$ \\
Trend & $<0.001$ \\
Rainfall & $<0.001$ \\
Nitrogen deposition & $<0.001$ \\
Nitrogen deposition and Land cover & $<0.001$ \\
Rainfall and Land cover & \\
\hline${ }_{\text {adj }}$ & \\
\hline
\end{tabular}




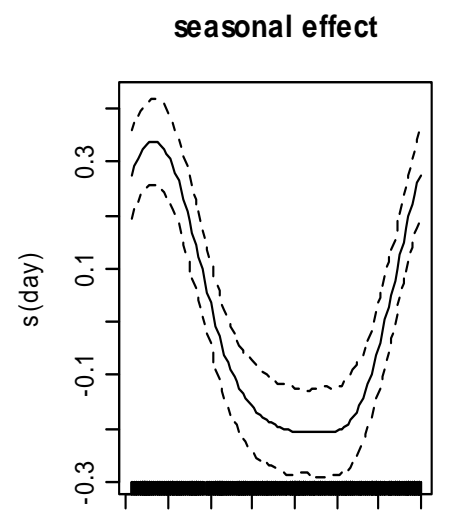

$\begin{array}{lllll}0 & 50 & 150 & 250 & 350\end{array}$

day
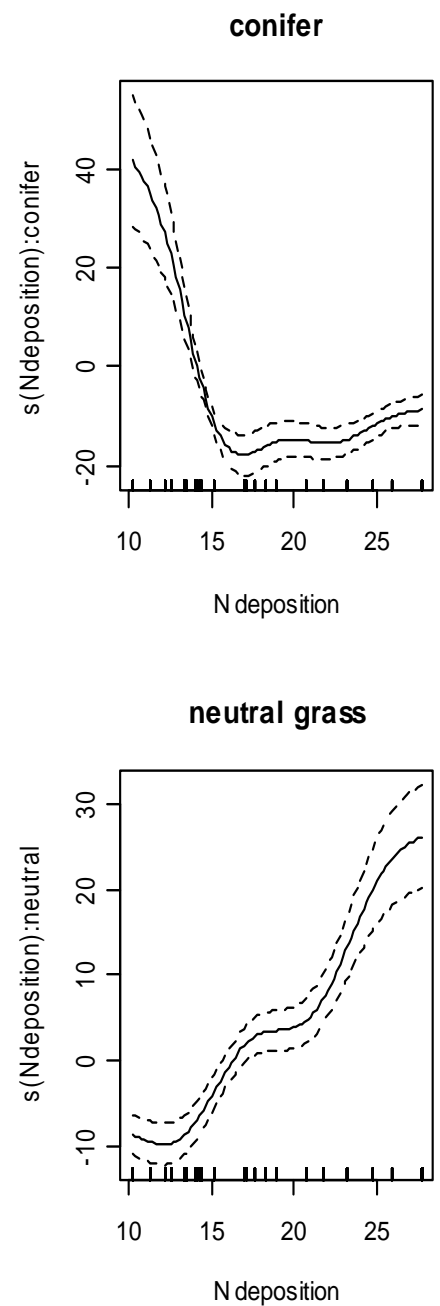
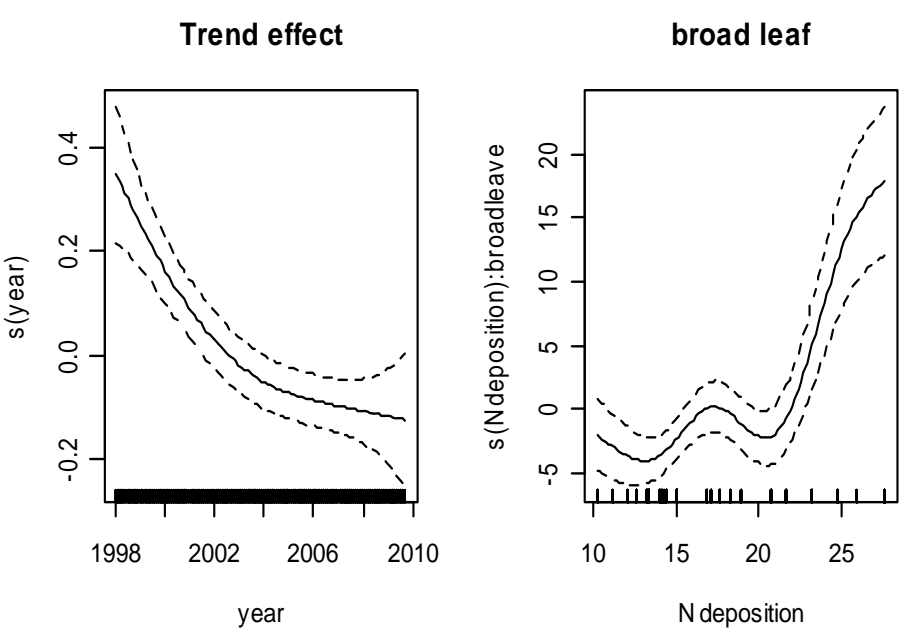

montane habitat
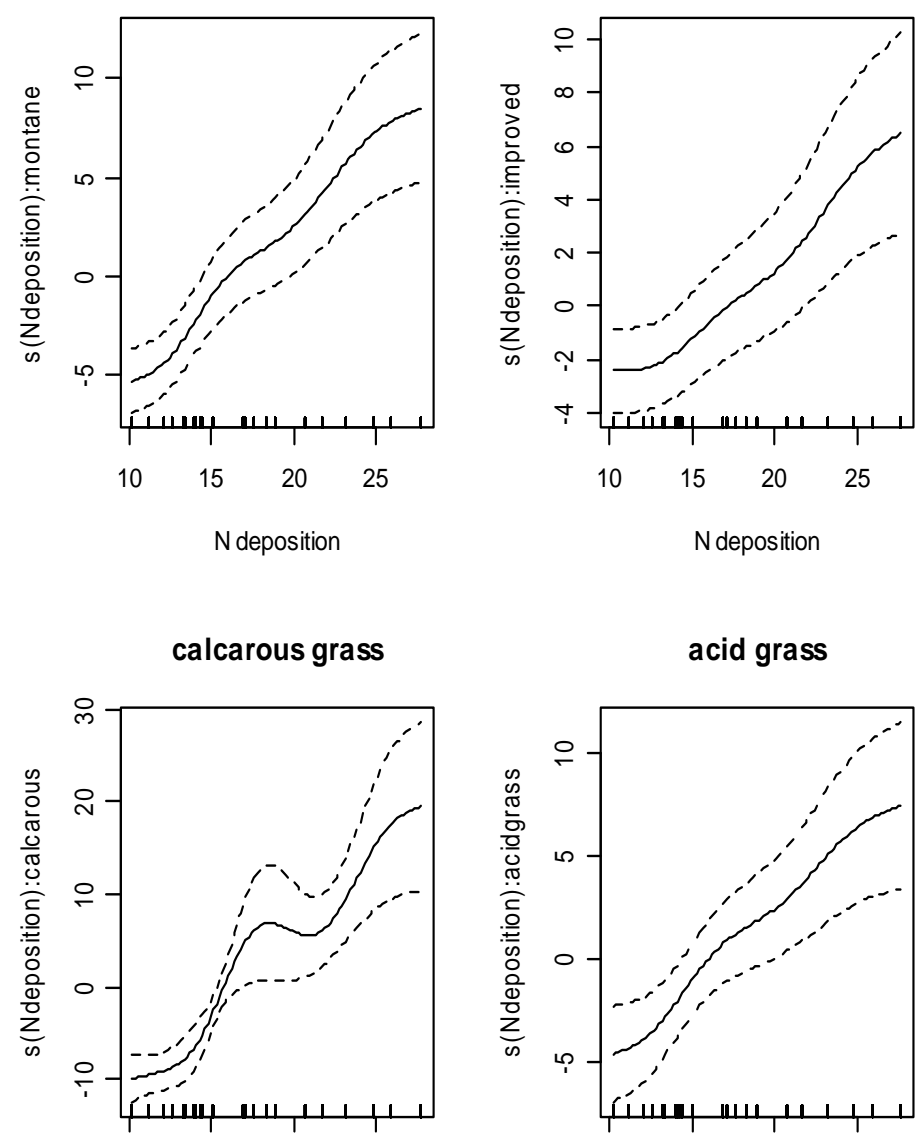

$\begin{array}{llll}10 & 15 & 20 & 25\end{array}$

$\mathrm{N}$ deposition acid grass

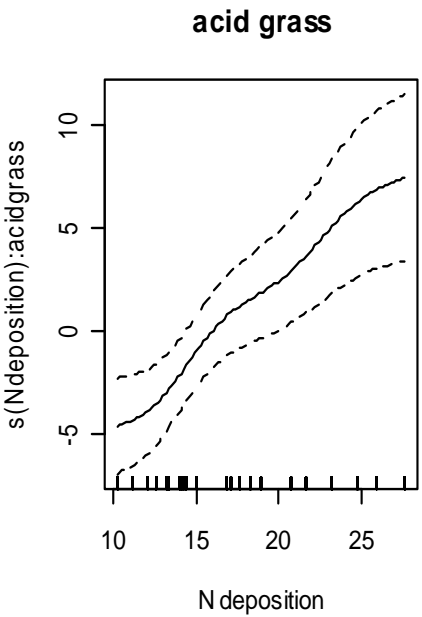

Figure 7. Plots of TON seasonal and trend patterns, interaction effects between land cover and nitrogen deposition on TON in the rivers. Dashed lines are two standard errors from the estimates. 


\section{Macrothink}

Figure 7 depicts results from model (4) showing smooth-factor interaction effects between nitrogen deposition and some categories of land cover on TON. Effect of nitrogen deposition is diminished in catchments with an increasing proportion of conifer woodland cover, while catchments with broad leaf woodland, neutral grass, acid grass and montane habitat land cover appear to enhance nitrogen deposition effects. However, interaction effects between nitrogen deposition and improved grass and dwarf shrub heat were not statistically significant.
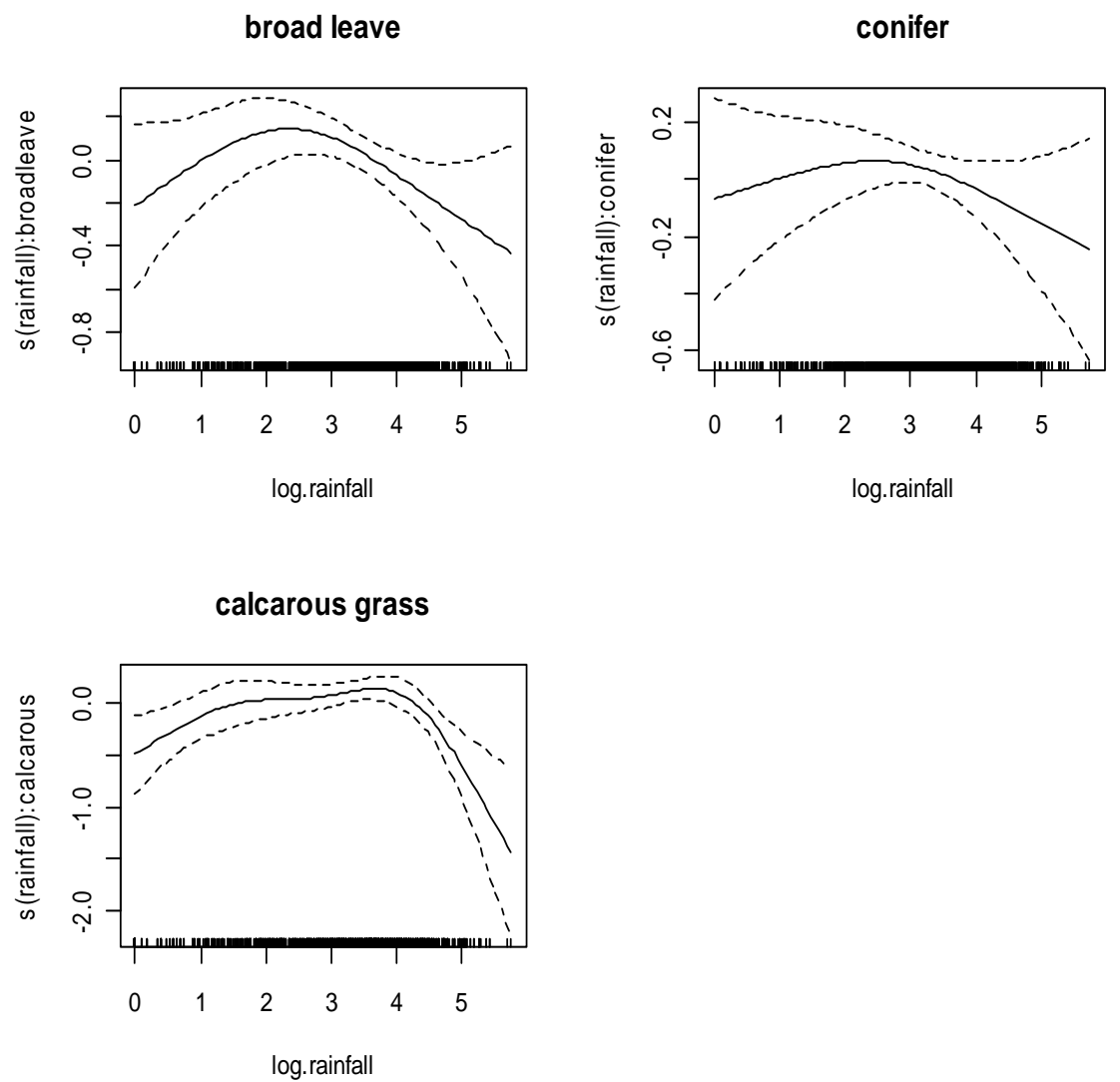

Figure 8. Effect of the interaction between land cover and rainfall on TON in river group.

Dashed lines are two standard errors from the estimates.

Figure 8 shows the effect of total weekly rainfall, given land cover, at the river sites. The effect of total weekly rainfall on TON at river sites differs depending on the predominant land cover type. Figure 8 indicates that rainfall has a neutralizing effect on sites where dominant land cover is broad leaf, conifer woodlands or calcareous grass. However, at sites where improved grass or acid grass is dominant, increased weekly rainfall leads to increased average TON concentrations. The same effects of rainfall on TON were observed in lochs and STW sites. Significant interaction effects between rainfall and nitrogen deposition on TON concentration were also observed in the three freshwater groups.

Levels of orthophosphate were found to be significantly influenced by some land cover types. The interaction effects between total weekly rainfall and land cover types were more pronounced in loch and STW sites but do not seem to significantly influence orthophosphate levels among the river sites. Generally, the smooth effect of weekly rainfall on 
orthophosphate levels in lochs and STWs are statistically significant. This does not seem to be true for the rivers as rainfall was not significant even when fitted without interaction with land cover.

We compared the full model (model (4)) with two sub models, one without the nitrogen and land cover interaction and the other without the rainfall and land cover interaction, in order to establish the significance of the two interaction terms respectively. In both cases, using the generalized likelihood ratio test, the full model (model (4)) was the better model, thus justifying the inclusion of the interaction terms in the model.

\section{Discussion}

The temporal and spatial analysis of the two water quality determinands provides a platform to assess simultaneously, changes in water quality trends - within year, between year, and between locations (or over space). For effective management of the freshwater environment, terrestrial catchment information is needed. We integrated this information into our models in order to investigate its association with variations in water quality in the Loch Lomond and the Trossachs National Park. Results from the site specific models highlight different seasonal and time trend patterns across sites with some similarities in seasonal pattern among sites in the same natural or functional group (river, lochs or STW). This suggested the need to group the sites into their natural classification and to model each group to produce estimates of seasonal and trend patterns. Differences in seasonal and trend patterns between the sites and groups could be attributed to the catchments' terrestrial components and activities. For instance, the different effects of mean daily flow observed for Rivers Forth and Endrick may highlight differences in catchment land use and geology. The base-rich rock and agricultural activities at the Endrick catchment could explain the observed positive association brought about by geochemical interactions and diffuse pollution while the neutralizing effect at the Forth River may suggest the existence of less base-rich rock and absence of anthropogenic activities within its catchment. Increasing trends were observed for orthophosphate in some river sites and the increase is more outstanding from 2006 in some of the rivers and loch sites.

The orthophosphate seasonal pattern observed among rivers in our investigation coincides with the pattern observed in the River Thames by Kinniburgh et al (1997) in their study of orthophosphate loads derived from agricultural sources and sewage treatment works in the river. They found that the proportion of sewage effluent in river flow increased by between $40 \%$ in summer months and $73 \%$ during droughts when there is less natural runoff and baseflow. This process seems to hold also in our study in freshwaters where sewage treatment effluents are discharged. Peak concentrations of both determinands are in the summer at the STW sites. Spatial effects are higher among sites that are in close proximity to sewage treatment works.

We adjusted for possible retention or uptake of deposited nitrate by the terrestrial ecosystems by fitting interaction terms between deposition and land cover categories. Our results support the findings of Curtis et al (2005) and Emmett et al (1993) of the existence of significant interactions between vegetation type and nitrogen deposition in relation to their effect on TON. Also, our findings are in line with those of Clark et al (2004) that the effect of nitrogen 
deposition on river TON concentrations declined with increasing conifer cover. However, a positive association was found between nitrogen deposition and TON in catchments dominated by broad leaf woodland, calcareous, acid, improved grassland and montane habitat.

\section{Conclusion}

Temporal and seasonal patterns of TON and orthophosphate in the freshwater bodies within the studied region differ, across sites and also by natural or functional groups of sites. TON levels are decreasing in rivers and lochs but increasing in STW sites. Orthophosphate concentrations declined till 2006, when average levels started to increase in rivers and lochs. Levels at STW sites are on the decline through the years. Spatially, TON and orthophosphate concentrations are higher in lochs and rivers located in the eastern part of the park. Different land cover types moderate the association of nitrogen deposition and rainfall with TON and orthophosphate levels in the water bodies.

\section{Acknowledgements}

We authors wish to thank NERC for funding this work (GE/9001170/1) and the Scottish Environment Protection Agency (SEPA) for supplying the data.

\section{References}

Bell, A. (2006). Introduction to the Loch Lomond \& the Trossachs National Park. [Online] Available: http://www.glasgownaturalhistory.org.uk/ll_papers/llproc_ab.pdf. (7 September 2009).

Centre for Ecology and Hydrology. (2000). Land Cover Map.

Centre for Ecology and Hydrology. (2010). Air Pollution Information Sysytem (APIS). [Online] Available: http://www.apis.ac.uk/. (10 August 2010)

Chakrabarty, D. (2006). Modelling Phosphosrus utilization by biotic components: A test case using two insoluble phosphate sources. Our Nature. 4:1-9.

Clark, M.J., Cresser, M.S., Smart, R., Chapman, P.J., \& Edwards, A.C. (2004). The influence of catchment characteristics on the seaonality of carbon and nitrogen species concentrations in upland rivers of Northern Scothland. Biochemistry. 68:1-19.

Curtis, C.J., Emmett, B.A., Grant, H., Kernan, M., Reynolds, B., \& Shilland, E. (2005). Nitrogen saturation in UK moorlands: the critical role of bryophytes and lichens in determining retention of atmospheric N deposition. Journal of Applied Ecology. 42:507-517.

Emmett, B.A., Reynolds, B., Stevens, P.A., Norris D.A., Hughes, S., Gorres, J., Lubrecht, I. (1993). Nitrate leaching from afforested Welsh catchments - interactions between stand age and nitrogen deposition. AMBIO. vol . 22, No 6.

European Commission. Council Directive 91/27/EEC of 21 May 1991 concerning urban waste water treatment. 
European Commission. Directive 2000/60/EC of the European Parliament and of the Council establishing a framework for the Community action in the field of water policy

Ferrier, R.C, Edwards, A.C., Hirst, D., Littlewood, I.G., Watts, C.D., \& Morris R. (2001). Water quality of Scottish rivers: spatial and temporal trends. The science of the Total Environment. 265:327-342.

Fisher, D.C., \& Oppenheimer, M. (1991). Atmospheric Nitrogen deposition and Chesapeake Bay Estuary. AMBIO Vol 20:3-4.

Gu, C. (1992). Cross validating non-Gaussian data. Journal of Computational Graphical Statistics. 1:169-179.

Heathwaite, A.L, Dils, R.M., Liu, S., et al. (2005). A tiered risk-based approach for predicting diffuse and point source phosphorus losses in agricultural areas. Science of the total Environment. 344:225-239.

Howden, N.J.K., \& Burt, T.P. (2009). Statistical analysis of nitrate concentrations from Rivers Frome and Piddle (Dorset, UK) for the period 1965-2007. Ecohydrol. 2:55-65. http://dx.doi.org/10.1002/eco.39

Johnes, P.J, \& Butterfield, D. (2002). Landscape, regional and global estimates of nitrogen flux from land to sea: Errors and uncertainties. Biochemistry. 57/58:429-476.

King, S.R, Baker, M.E., Whigham, D.F., Weller, D.E., Jordan, T.E., Kazyak, P.F., \& Hurd M.K. (2005). Spatial considerations for linking watershed land cover to ecological indicators in streams. Ecological Applications. 15(1):137-153.

Kinniburgh, J.H, Tinsley, M.R \& Bennett, J. (1997). Orthophosphate concentration in River Thames. Journal of the Chartered Institute of Water Environmental Management 11:178-185.

Lee, K., \& Helsel, D. (2005). Statistical analysis of environmental data containing multiple detection limits: S-language software for regression on order statistics. Computers in Geoscience, 31:1241-1248.

Lock Lomond and the Trossachs National Park. (2005). State of the Park report.

Paiseley, M.F., Walley, W.J., Nikhade, J. \& Dils, R. (2003). Identification of the key biological indicators of nutrient enrichment in Rivers for use in predictive/ diagnostic models. Diffuse Pollution Conference Dublin.

Ricklefs, R.E. (1993). Species Diversity in ecological Communities: historical and geographical perspectives. The University of Chicago Press, London.

Weyhenmeyer, G.A., Jeppesen, E., Adrian, R., et al. (2007). Nitrate-Depleted on the increase in shallow Lakes. Limnology and Oceanography. 52(4):1346 -1353.

Wood, S.N. (2000). Modelling and smoothing parameter estimation with multiple quadratic penalties. Journal of Royal Statistical Society B. 62:413-428. 
Wood, S.N. (2002). GAMs with integrated model selection using penalized regression splines and applications to environmental modelling. Ecological Modelling 157:157-177.

Wood, S.N. (2004). Stable and efficient multiple smoothing parameter estimation for generalized additive models. Journal of American Statistical Association. 99:673-686. http://dx.doi.org/10.1198/016214504000000980

Wood, S.N. (2006). Generalized Additive Models: an introduction with R. Boca Raton: Chapman and Hall-CRC.

Wood, S.N. (2008). Fast stable direct fitting and smoothness selection for generalized additive models. Journal of Royal Statistical Society, Series B. 70 (Part 3): 595-518. 